\title{
STABILIZATION OF THE SHAPE MEMORY EFFECT IN NiTi: AN EXPERIMENTAL INVESTIGATION
}

\author{
B. Erbstoeszer, B. Armstrong, M. Taya, and K. Inoue \\ Center for Intelligent Materials and Systems, Department of Mechanical Engineering, University of \\ Washington, Box 352600, Seattle, WA 98195
}

(Received December 28, 1999)

(Accepted in revised form February 2, 2000)

Keywords: NiTi; One-way shape memory; Thermo-mechanical cycles; Conditioning

\section{$\underline{\text { Introduction }}$}

Over the last 20 years or so, shape memory alloys have become well known for their ability to undergo large shape changes that traditional metals could never do. One such alloy, NiTi, has been of particular interest due to it's high efficiency (when compared to other SMA's) to convert thermal energy into mechanical energy. While NiTi is currently used in industry, its use is hindered by an extreme sensitivity to processing techniques. Certain parameters such as alloy composition, annealing procedures and various loading conditions can improve the shape memory effect or completely make it disappear. Many studies have focused on these variables. Of particular interest to this study is the one-way shape memory effect (OWSME) after the NiTi has been cycled (deformation followed by recovery) many times. It is very desirable to find a processing technique that would stabilize the OWSME and make it repeatable after many cycles. This paper explores these parameters in hopes of finding an optimal process to stabilize the shape memory effect in NiTi.

Many studies have been conducted examining the cyclic behavior of NiTi. Most common are studies done on pseudoelastic NiTi $(1,2,3)$ and on the two way shape memory effect (TWSME) $(4,5,6,7)$. However, very few have explored these cyclic effects on the OWSME. One study that was conducted on the OWSME used wire samples and carried tests out to 100 cycles (8). It was reported that the recovery strain was reduced to $93.4 \%$ and $81 \%$ of the total strain when total strains of $6 \%$ and $8 \%$ were used, respectively over the 100 cycles. (Note, that these values will differ from ours since they used "hard" cycles with a fixed maximum strain where as we used "soft" cycles with a fixed maximum stress.) This displays the degradation of the shape memory effect that hinders NiTi's use. After this work, another study was performed that investigated a conditioning technique to try to stabilize the shape memory effect (9). Their research recommended that after SME (strain-heat-recover-cool-repeat) cycling the NiTi 30 times at $6 \%$ strain, a stable strain range was obtained for strains less than $6 \%$. This was only shown over a very few cycles and in wire samples.

It is our hypothesis that some form of "conditioning" may be performed on NiTi after annealing to improve its cyclic shape memory properties. The result will be a protocol that can be applied to NiTi before its service use. In doing so, it is important to define a few performance criteria that are considered indicative of "good behavior" and clarify what will hopefully be stabilized:

- Stabilization of the maximum, minimum and recoverable strain over a low number of cycles. 
Unconditioned NiTi

a
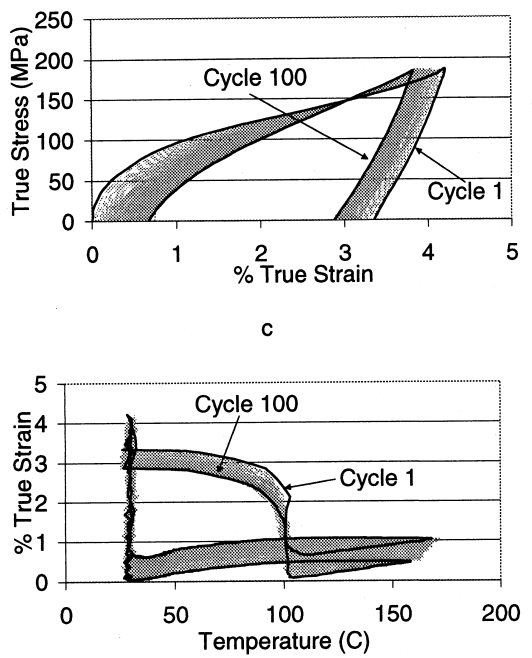

e

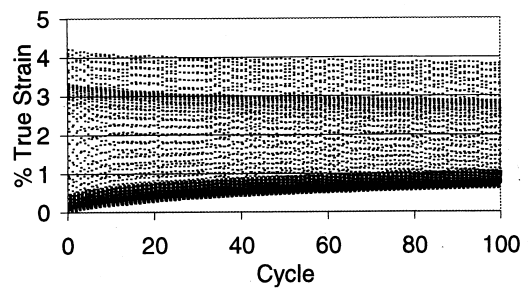

Conditioned NiTi

b
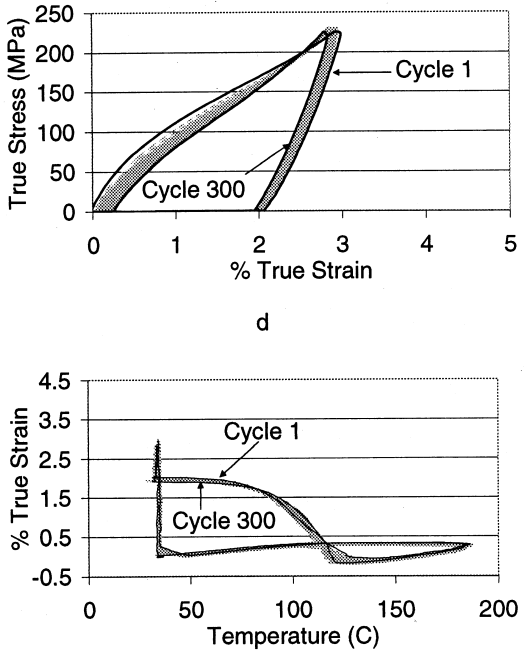

f

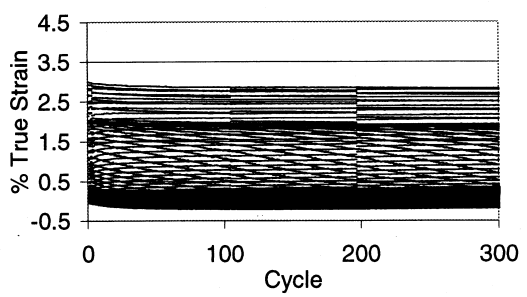

Figure 1. Comparison charts of conditioned and unconditioned NiTi samples after 300 and 100 cycles, respectively.

- Maximum strain range during loading and full recovery upon heating.

These are the criteria that were used to compare the results of the various experiments. To compare the various parameters, plots were made that displayed the cyclic strain behavior. Two quantities, strain amnesia (or creeping) and strain hardening, were both able to be measured from the data collected. Strain amnesia occurs when the material does not fully recover back to its original shape, thus over many cycles there is a noticeable strain accumulation. Strain hardening is observed when the maximum strain (which occurs when the applied stress is also a maximum) decreases over the number of cycles for the same applied stress. Both of these quantities are observed in Figure 1a and 1b.

\section{Experimental Materials and Procedures}

\section{$\underline{\text { Specimen Preparation }}$}

The specimens for this study were made from NiTi ingots a composition of Ti-49.9 atomic\% Ni. From the 8-inch diameter ingot, 2.5-inch diameter billets were formed by forging the raw NiTi material. The billets were then hot rolled into rods with a nominal diameter of .55 inches. The hot rolling occurred 
at approximately $900^{\circ} \mathrm{C}$, which produced a very fine (approximately ASTM 6) grain size. After the rods were formed, they were solution annealed in air at $85^{\circ} \mathrm{C}$ for 20 minutes followed by a water quench. The rods were then drawn at room temperature to contain approximately $30 \%$ cold work. The specimens were finally machined into a cylindrical dog bone specimen with a test section length of $31.1 \mathrm{~mm}$ and a diameter of $6 \mathrm{~mm}$.

\section{Annealing Heat Treatment}

After the specimens were processed and machined into dogbone shapes, they were subjected to an annealing heat treatment, sometimes known as the "shape memorizing" treatment. The annealing heat treatments were performed in salt baths followed by a water quench. A temperature of $475 \mathrm{C}$ for 5 minutes was found to be the optimal annealing treatment to alloy for stabilization of our NiTi specimens.

\section{$\underline{\text { Tensile Test Frame Set-Up }}$}

To perform the tension tests, an 8521S Instron machine was used with .5 inch diameter collet grips. To obtain the strain measurements, an Instron extensometer with a gauge length of $10 \mathrm{~mm}$ and a range of $+/$ - $1 \mathrm{~mm}$ was used. For the temperature measurements, a T-type thermocouple was fastened to the specimen by wire wraps to ensure contact throughout the duration of the experiment. To heat the specimen, two focussed 1500 watt infrared line furnaces (heat lamps) were used that faced each other with the specimen in the focal line. A PID control box was used to control the heating rate, power and time duration. A cooling fan was also integrated to decrease the time necessary to cool the specimen back down to near room temperature.

\section{The Comparative Shape Memory Effect Cycle}

When cyclic behavior of a shape memory alloy is discussed, a cycle typically includes the following input variables: a) loading to a point where a residual strain is present after the load is removed, i.e. an apparent deformation has occurred which is accommodated by detwinning of the martensite phase; $b$ ) heating to a temperature at which the material returns to its memorized shape in the parent austenite phase and maintains that shape upon cooling. This is called a shape memory effect (SME) cycle.

In our case the cycle lasted 6 minutes and was comprised of 4 phases. First is loading, which occurs at room temperature when the NiTi is at a temperature below $\mathrm{M}_{\mathrm{f}}$. The load applied is sufficient to change the twinned martensitic microstructure to detwinned martensite. This is observed macroscopically by a duck-tail on the stress vs. strain curve. Thus upon the completion of the second phase, unloading, a residual strain is left in the specimen. The third phase is heating, where heat lamps are used to heat the specimen well above $\mathrm{A}_{\mathrm{f}}$ to assure maximum allowable shape memory recovery. Finally, in the last phase, the specimen is air cooled with a fan to minimize the time required for testing. Soft cycling (1) was the loading mode used which means that for each cycle, the same maximum stress was reached (this is opposed to hard cycling, where the same maximum strain is reached for each cycle). This way strain accumulation could be monitored. 


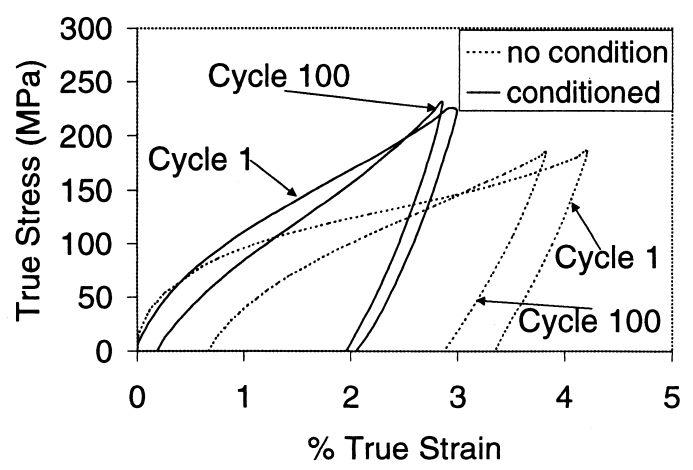

Figure 2. A comparison of True Stress vs. \%True Strain for the $1^{\text {st }}$ and $100^{\text {th }}$ cycles for an unconditioned and conditioned specimen.

\section{Conditioning Investigation}

\section{Explanation of Conditioning Method}

As stated earlier, it is our hypothesis that a conditioning treatment applied after annealing will stabilize the cyclic shape memory properties of NiTi. Many methods were briefly investigated in our lab and qualitatively compared, but a method termed as isoforce conditioning consistently gave the best results.

For our ideal conditioning method, a load of approximately $8 \mathrm{kN}$ was applied to a specimen which was already annealed with our optimal annealing heat treatment $(475 \mathrm{C}$ for 5 minutes in a salt bath followed by a water quench). Then the specimen (which was loaded at room temperature) was subjected to 10 thermal cycles that ranged from below $\mathrm{M}_{\mathrm{s}}$ to above $\mathrm{A}_{\mathrm{f}}$. The load applied produced a true stress of $300 \mathrm{MPa}$ on the first cycle. This stress was picked since it was $30 \%$ higher than the maximum stress (230 MPa) that was decided to be used in the comparative SME cycles. The thermal cycles were run just as they were in the SME cycle, thus one isoforce conditioning cycle would also take 6 minutes.

Once the 10 loaded thermal cycles were completed, the material was unloaded and thermal cycled for nearly 80 stress-free thermal cycles as part of the conditioning treatment. These cycles were run to ensure that the material had fully recovered to a stable unloaded position before the comparative SME cycles were performed.

For the SME cycles in the isoforce conditioning investigation a maximum stress of $230 \mathrm{MPa}$ was used instead of $180 \mathrm{MPa}$ as used in the unconditioned case. The larger stress was needed because the conditioned material was significantly stiffer after the isoforce conditioning treatment. Also, $300 \mathrm{SME}$ cycles were executed instead of just $100 \mathrm{SME}$ cycles as used in the annealing study. This was done to further investigate the cyclic behavior at a larger number of cycles. Similar data was collected and plots were made to observe the effect of annealing and conditioning on NiTi, which are shown in Figure 1.

\section{$\underline{\text { Discussion and Conclusions }}$}

From a qualitative comparison of the charts, it is easy to see the general stabilization that has occurred upon applying the isoforce conditioning after annealing. It is important to notice the reduction in strain amnesia and strain hardening in Figure 1a and $1 \mathrm{~b}$. The strain stabilization is also easily noticed in Figure $1 \mathrm{e}$ and $1 \mathrm{f}$ where the strain is virtually stable after cycle 40 in the unconditioned case. To combine the 
TABLE 1

Comparison of Various Calculated Parameters for Unconditioned and Conditioned NiTi after 100 and 300 Cycles

\begin{tabular}{lccc}
\hline & $\begin{array}{c}\text { Unconditioned } \\
(0-100 \text { Cycles })\end{array}$ & $\begin{array}{c}\text { Conditioned } \\
(0-100 \text { Cycles })\end{array}$ & $\begin{array}{c}\text { Conditioned } \\
(0-300 \text { Cycles })\end{array}$ \\
\hline Total Strain Range Cycle 1 & 4.21 & 2.99 & 2.99 \\
Total Strain Range Cycle 100 or Cycle 300 & 3.16 & 2.67 & 2.61 \\
\% Reduction in Total Strain Range over \# of Cycles & $24.90 \%$ & $10.70 \%$ & $12.70 \%$ \\
Recoverable Strain Range Cycle 1 & 3.33 & 2.04 & 2.04 \\
Recoverable Strain Range Cycle 100 or Cycle 300 & 2.18 & 1.74 & 1.64 \\
\% Reduction in Recoverable Strain Range over \# of & $34.50 \%$ & $14.70 \%$ & $19.60 \%$ \\
\hline
\end{tabular}

Note that strain range values are given in $\%$ true strain.

plots and make the comparison easier, a plot of True Stress vs. $\%$ True Strain for the $1^{\text {st }}$ and $100^{\text {th }}$ cycle of each test is shown in Figure 2.

It follows from Figure 2 that the repeatability of the conditioned NiTi during SME cycling has been improved over the unconditioned NiTi. For a more quantitative analysis, various parameters were calculated and are shown in the following table.

As a result of our research, the various parameters investigated converged to an optimal annealing and conditioning treatment. The optimal parameters are summarized as follows:

- The annealing heat treatment that was found to produce the most stable one-way shape memory effect in all materials was a 5 minute $475 \mathrm{C}$ salt bath, followed by a water quench.

- Isoforce conditioning proved to be the most beneficial conditioning technique to stabilize the one-way shape memory effect.

While a perfectly stable and repeatable one-way shape memory effect in NiTi was not shown (which may not be attainable) in this research, a significant improvement was made. With the proper annealing heat treatment and conditioning method, the OWSME in NiTi was remarkably stabilized. It is important to note though that this did come at the cost of reducing the strain range. This fact must be considered when using NiTi to design with. Apparently, only small ranges of recovery are possible if many repeatable cycles are desired.

\section{Acknowledgments}

This research was supported by the Boeing Company and DARPA as a part of the SMAC program. The NiTi specimens were provided by Mr. Alex Popoff of MetalTex. The tests were carried out at the Washington Technology Center at the University of Washington.

\section{$\underline{\text { References }}$}

1. B. Strnadel, et al., Mater. Sci. Eng. A203, 187 (1995).

2. S. Miyazaki, in Engineering Aspects of Shape Memory Alloys, ed. Deurig et al., pp. 394-413, Butterworth-Heinemann Ltd. (1990).

3. B. Strnadel, et al., Mater. Sci. Eng. A202, 148 (1995).

4. Wayman, Deurig, in Engineering Aspects of Shape Memory Alloys, Deurig et al., pp. 3-20, Butterworth-Heinemann Ltd. (1990) 
5. H. Funakubo, Shape Memory Alloys, Gordon and Breach Science Publishers (1984).

6. H. Scherngell and A. C. Kneissl, Scripta Mater. 39, 205 (1998).

7. C. Liang and C. A. Rogers, J. Intell. Mater. Syst. Struct. 8, 314 (1997).

8. W. B. Cross, et al., Nitinol Characterization Study, NASA CR-1433, Sept. 1969.

9. Y. Sekiguchi, et al., J. Fac. Eng. Univ. Tokyo. 36, 777 (1982). 